\title{
The Integrative Effect of Electronic Data Processing
}

\author{
This paper was first published in elektronische datenverarbeitung 1(1)1959:14-19.
}

DOI 10.1007/s12599-008-0020-5

\section{The Author \\ Karl Heinz Kettner \\ Duisburg-Meiderich \\ This article is also available in German in print and via http://www.wirtschafts informatik.de: Kettner KH (2008) Der Integrationseffekt elektronischer Datenverarbeitung. WIRTSCHAFTS- INFORMATIK. doi: 10.1007/11576-008- 0126-x.}

In practical use of commercial electronic data processing questions regarding the essential meaning of this expression are of decisive relevancy. Although a multitude of publications in this area exist, especially economic treatment of this issue is missing. The available literature mainly considers the technical construction of electronic computers, which is understandable in view of the great physical achievement of these devices. The fact that electronics is used to reach high speeds of operation does not account for the term "electronic data processing". The fundamental innovation is to take advantage of these high speeds combined with high memory capacities in order to achieve integrative effects. In that light the term "electronic data processing" changes to "(electronic-)integrated data processing”. Its close link to the fundamental conception of economic performance in general and the notion of the organization in particular sets the theoretical stage for using electronic data processing devices in business administration.

This is because automation does not only result from progress in communication engineering and electron physics alone but has in fact been rendered possible by fundamental research in cybernetics and communication theory. These disciplines deal with general rules for relationships between individual institutions and analyze the possibilities of optimal aggregation and harmonization. Thus, they become a "generalized organization and control theory" (Wiener 1948). The purpose of organization is "to create an organism, the regulation of relationships between individual institutions. The parts of an organization have to be adjusted to the intended primary and secondary purposes; then the term 'efficient' is justified” (Kalveram 1953, p. 259). This statement, written by a German business scientist, already covers the major aspects that have to be observed and that are analyzed by researchers of cybernetics.

In modern use these are called:

1. Information

2. Control and regulation

3. Effective aggregation or integration.

Kalveram (1953) summarized the first two of these aspects with the expression "regulation of relationships".

In terms of general organizational theory, the notion "organization" refers to an effective, teleological aggregation or integration of objects with objects, subjects with objects, or subjects with subjects. The notion includes the efficient organization of a company as a case of higher organization. Optimal organization is an integrated process. It implies optimal information flow and optimal control, which means adaptation to previously set objectives. The highest organizational forms are marked by automatic adaptation and modification of objectives when conditions change.

\section{General organizational models}

An entire organization can be reduced to very simple elements. Organizational systems of the lowest level are composed of single elements only, whereas higher ones are made up by multiple elements. Single elements are aggregated to an efficiently working organism by means of an ideal information flow and effective control mechanisms. This applies to basic technical devices, to larger technological facilities and to the human body as well as to microeconomic, macroeconomic, and sociological forms of organization.

The following text describes individual organizational elements and basic organizational forms together with the transition to more complex systems (Deutsch 1951a). This also reveals the basic theoretical principles of automation and electronic data processing.

The simplest organizational element is the transformer, an element of open control which transforms information into other information. Concrete illustrations of this particular element are for instance - technologically: the rectifier,

- economically: the order acceptance process which transforms external into internal orders.

Another simple element is a sorting device, which again constitutes a system of open control. In this case, however, the system itself already makes sorting decisions by means of built-in decision criteria. Simple examples are

- technologically: a juice extractor, or a punch card sorter,

- economically: the handling of company mail.

Basic elements with self-control work by continuously comparing their operations with previously set objectives. Fig. 1 shows a closed control system for sorting.

The system arrives at sorting decisions on the basis of built-in criteria. However, there is an additional control of these decisions by a feed-back mechanism. In this way, wrong decisions are corrected automatically.

More complex organizational forms have more target parameters which have to be chosen depending on the input information. This requires the existence of a memory in the broadest sense, which includes all possible target parameters. Storing these parameters can be seen as a kind of learning process. Nevertheless, 
this type of learning, i. e. choosing among target parameters, is different from the learning process that takes place when such a system continuously determines new target parameters from the collected data.

The latter is only possible with the highest organizational forms because it requires the existence of consciousness.

Fig. 2 shows a simple overall organization (Deutsch 1951b), which is depicted as a communication model and partly annotated with concrete identifiers. These identifiers explicitly reveal that it is in fact an extensive communication model: it applies, for instance, to technical equipment (electronically controlled antiaircraft artillery AAA) as well as to an economic organization (sales department). In column I, the figure shows the elements that work as a simple feedback system with fixed target parameters (Radar-AAA). Column II depicts those units which can be taken as a memory and which modify the target parameters (flight path prediction). Column III contains the units of consciousness, the reflective cycles of target modification. The latter are not a standard component of contemporary electronic computers. Thus, the limits of the current state of the art are already defined.

Phrased in economic analogies, column I shows the order acceptance process of a manufacturing company which modifies incoming orders into standardized internal orders and eventually effects shipping. Column II illustrates the semi-automatic or tactical modifications of the target parameters in the sales manager's area of responsibility. Column III symbolizes the 'long-run' planning functions of the plant management.

From this global view, the following most general definition of the organization results: Organization controls the interaction of a group of elements... (a company's departments, machine parts, organs in the human body, people in a social group, etc.) in order to reach or retain certain target parameters (e. g. a working standard, standard values, time allocations, or complex target parameters).

According to this definition, organization can be considered as the integration of single parts and functions to a targetoriented whole. An organization's degree of effectiveness is determined by its degree of integration. Thus, integration and efficiency are intimately connected because "efficiency requires all institutions and

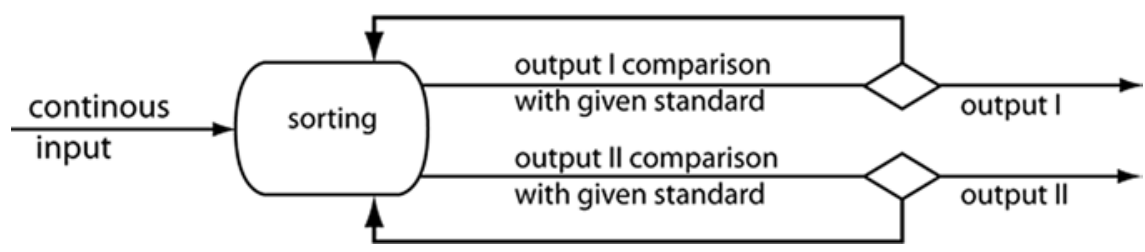

Fig. 1 Sorting control system

processes to reasonably subordinate under the intended economic objectives" (Kalveram 1953, p. 85).

Duplication of work, jams, inorganic branching, nesting, and fragmentation of tasks are characteristics of poorly integrated systems. Opposed to this, effective workflows in a closed control system with consideration of the most efficient paths are characteristics of an ideal "integrated system", and thus of an ideal organization. In this sense, the pursuit of integrated systems is a fundamental component of economic theory and of management practice as well. However, due to the restriction of means and methods the aspired objective has still not managed to catch up with the theoretical optimum. In business, electronic-integrated data processing shifts the aspired objective to a higher level.

Improving efficiency by integration is the theoretical foundation and the mental framework of automation in general and electronic automation in particular.

By means of these tools, which have been compiled by cybernetics, it is possible to imagine a theoretical system of economy in which the development and application of electronic data processing units for commercial use are consistently classified if the principles of integrated data processing are observed. Hence, it can be concluded that an effective use as an "organizational machine" can only be guaranteed if these principles are implemented.

\section{Economic activity as an integrated process}

Economic activities are continuous and goal-oriented processes. They aim at a satisfaction of needs which is regulated by prices via supply and demand or by a central planning institution. In economy, all processes are interdependent. In the state of equilibrium they form a harmonic whole. Disturbances of this equilibrium result from control failures. This can clearly be seen from the example of the well-known 'pork cycle'. Note: This failure of supply and demand, which was observed on the pork market before World War I, is caused by the fact that suppliers of goods with long production periods (pig breeding) overestimate an increase of demand and raise production excessively. When the goods then reach the market after a long period of time, there is a huge decline in prices due to oversupply. Then, the recession is overrated and production highly reduced which makes prices rise highly etc. (Fig. 3).

The failure of control results from the fact that the suppliers do not learn from mistake (Schneider 1949). In short, one can say that the economy as a whole is an integrated process.

Single enterprises are part of the economy as a whole. They are organically embedded in it. An enterprise is marked by the integration of various sectors of economic activity. Only the combination of procurement, financial sphere, internal production of goods and services, and the sales section results in the overall picture of an economic organization - especially of the one corresponding to our form of the economy: the enterprise. This structure is only viable "as long as it is well designed and composed effectively. In this context, it is said to be an indispensable imperative to balance the parts of an organism" (Junkersdorff 1957, p. 193).

This means that an enterprise principally has to be considered as a whole. Thus, at this point it can be concluded again that running a business is a continuous process for the purpose of producing goods and services at minimal cost - or, if one wants to put it that way, maximal profit - which is regulated by efficiency quantified in terms of profit. In short: running a business is an integrated process, organically embedded in the integrated process of the economy as a whole.

Such an overall conception of economic activity corresponds to the view of multiple small-scale integrated systems, which as a whole again characterize the integrated process of an enterprise in harmonic adjustment. Each sector of the operational activities, be it internal production or marketing or finance, consti- 


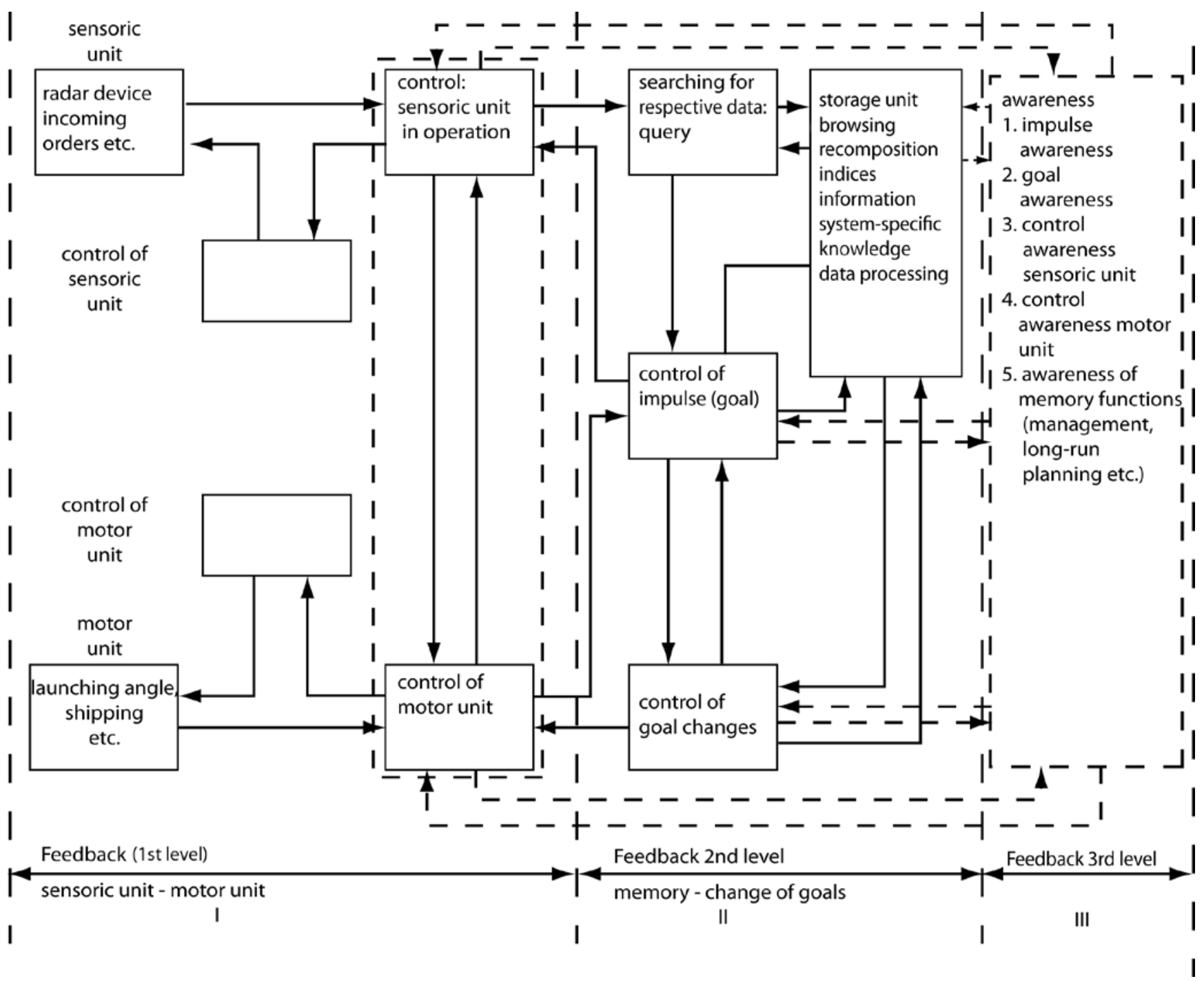

Fig. 2 Communication model

tutes an integrated system and a holistic process itself.

Even when differentiating in greater detail, the fundamental principle does not change; again and again the result must be an integrated system, which is embedded in the integrated system of the next higher order. From this point of view, the wage and salary sector of an enterprise is an entire whole, a continuous process with fixed rules and harmonized activities. In other words, each closed sector of an enterprise is an integrated process organically embedded in the integrated process of the enterprise.

So far, we have mentally designed the structure of economy as a holistic entity, in which each part is an integrated system that combines with other parts to make up a more comprehensive integrated system. However, when looking at reality, it becomes clear that there are plenty of obstacles hindering the practical realization of these fundamental tendencies.

\section{Specialized division of labor}

We have shown that the "integrated system" is the major characteristic of any economic activity and the aim of every organization. However, it can already be seen in the field of the corporate organizer that there are obstacles against these tendencies which had to be accepted so far. The reason for this is that even in industrial administration the specialized division of labor has come into effect and mainly resulted in a loss of holistic experience (Mayer 1956, p. 671). As, in the growing administration sector, a single person generally cannot deal with one functional area alone due to physical and control-related restrictions, groups and departments had to be created.
However, these are usually inconsistent with the respective overall functional area. Often they form closed sectors which are not identical to a complete field of activity. Thus, effective workflows usually cannot be assured. Phenomena like accumulation of tasks, interruptions or duplication of work cannot always be avoided and thus constitute a source of permanent irritation. The human being no longer suffices as a regulating element for one functional area of an enterprise. "In the process of increasing workloads [...] the scope of organizational units decreases. Consequently, the personnel factor, its capacity, determines form and size considerations of corporate department structures in interdependency with factual and technical circumstances" (Gutenberg 1951, p. 190). For this reason, the structure of the organization is mainly based on a separation of authority. In such structures 
there are usually no effective possibilities to combine separate organizational units. The organization cannot live up to its true character. Although a small work group may work very effectively in this way, the organization's objectives are not met.

Furthermore, in administrative processes machines for single activities, like traditional typewriters, calculators, or punch card machines, have created separate working areas and lead to a disintegration of specific tasks. It has to be pointed out that punch card machines with their potential for batch processing highly contributed to the efficient organization of economic activity; but also in this area owing to the technology's insufficient perfection - humans only partly benefited from the technology and were deprived of the integrity of work instead.

\section{Electronic data processing as means of integration}

As mentioned earlier in this text, electronic data processing belongs to the field of "automatic control". Automatic control or automation in the broader sense can be divided into two virtually distinct fields. As the term "automation in the broader sense" already implies, one of these fields is called "automation in the narrow sense", or "automation" in short.

This refers to the mere technological application forms in production, or as Canning (1956, p. 4) phrases it, "use of automatic techniques for an integrated materials handling and processing operation". The second field is called "integrated data processing (IDP)", or more specifically "electronic-integrated data processing (EDP)". Both of these integrated systems can be linked with one another.

Technically, automation is merely the continuation of mechanization. Mechanization in its present form, which has not been completed yet, freed humans from parts of their power-generating function. Single or multiple tasks are carried out mechanically. Here, the technical progress that gave rise to automation led to mechanical integration, mainly due to the use of electronics. "Thus, the most important methodological principle of automation is the integration of discontinuous single processes to a combined, smooth overall process" (Pollock 1956, p. 6).

In that light, automation does not only mean technical progress but also an orga-

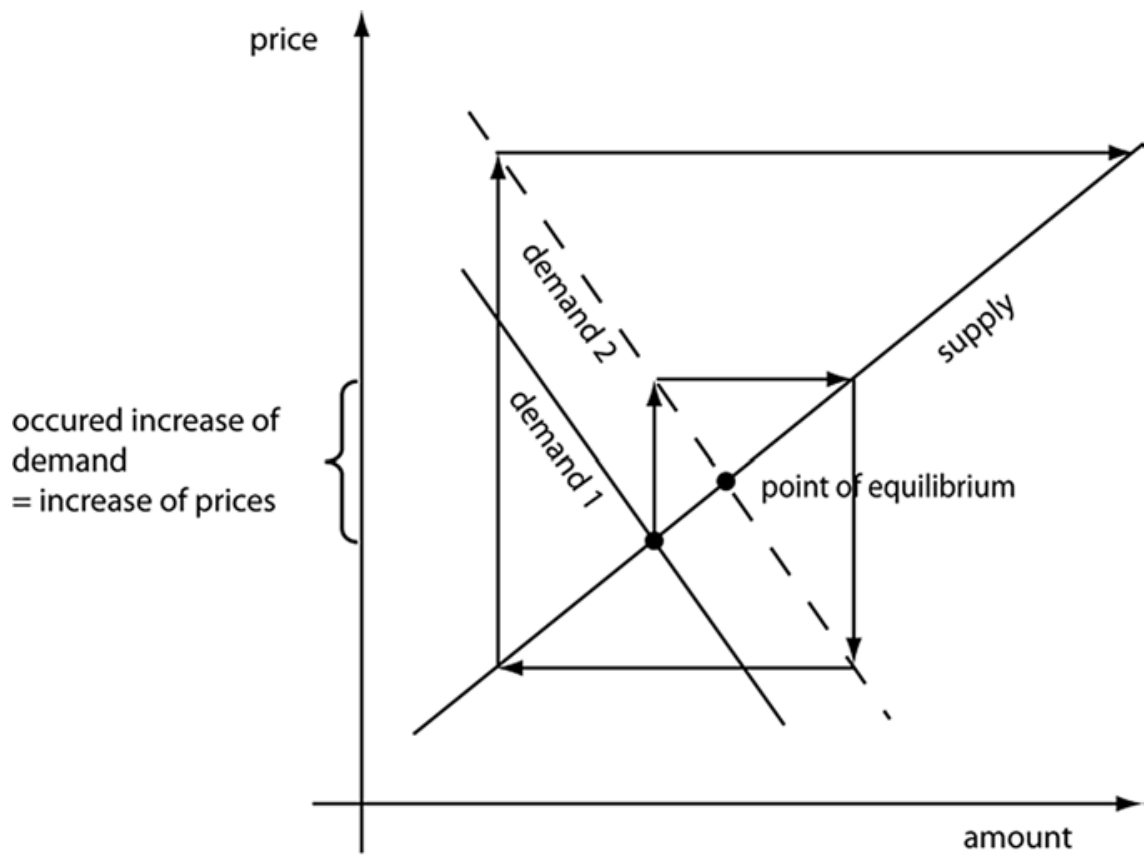

Fig. 3 Porc cycle

nizational and economic paradigm. In conclusion the previous arguments lead us to the following statements:

1. Integration as a characteristic of an efficient organization results from a general organizational theory based on cybernetic tools.

2. In the fundamental laws of the economy, integration constitutes a decisive factor.

3. Automation as a theoretical system requires the organizational realization of integration. This includes an optimal structure of business processes, a maximum of continuity, minimal cost and minimal effort in realizing the necessary tasks. This means that all tasks currently carried out by humans in cooperation with machines must eventually be transferred to machines completely, thus freeing the human from his makeshift function.

4. For administrative tasks, automation as a theoretical system requires renunciation from fixed department structures and the realization of effective workflows within an accounting sector or functional area without consideration of department borders.

5. Accepting this theoretical foundation, the analysis of work is by no means obsolete. Quite the contrary, even in administration there are tasks that have to be split up into their smallest measurable parts. However, a synthe- sis must then ensue; a reunion of the repetitive tasks must result in an automation of a closed ensemble (Deutsch 1956, p. 479).

The usage of electronic data processing devices allows for realizing these fundamental thoughts - even demands them due to its inner character. In the process of planning accounting systems the whole company has to be seen as an integrated whole that works towards a collective aim set by the top management. All operational areas are considered to be part of one consistent task. "Seen from the point of view of data processing the aim is realizing a stable information flow throughout the whole company" (Canning 1956, p. 71).

Electronic data processing helps lifting the organization to a higher level of integration.

The disregard of the fundamental tendencies immanent to this development bears the risk of acting against the fundamental principles of the organization and of economic performance.

From this point of view it is understandable that electronic data processing requires a different treatment than punch card machines or other organizational devices. Even electronic calculation is not the decisive feature of electronic data processing. Card punchers with arithmetic capabilities, electronic accounting units, or scientific computers are not "electronic data processing machines". This differ- 


\section{Abstract \\ Karl Heinz Kettner \\ The Integrative Effect of Electronic Data Processing}

Electronic data processing systems have been constructed based on the results of cybernetics and communication theory. They interpret the combination of several constructs as integrated systems that form integrated systems of a higher degree. This corresponds to the way modern economics looks at corporate functions, enterprises, the economy...

This fundamental tendency is reflected by the idea that the most important factor in electronic data processing systems is not the speed of operation but the integrative effect. Therefore it is necessary to arrange workflows in a closed control system, under consideration of the most rational path. Thus IDP advances the aims of business organization to a higher level and at the same time provides means for reaching these aims.

Reprint of an article from elektronische datenverarbeitung 1(1)1959:14-19. The original summary has been revised by the editorial staff.

Keywords: Integration, Electronic data processing, Integrative effect ence has to be pointed out explicitly. These tools are used to save time in solving tasks but they do not have the previously emphasized effect of integration. However, commercial data processing systems are about speed, but even more about the integration thus made possible. In this context, integration requires a one-time input of a functional sector's complete original data as well as processing and storage of this data until all results and a one-time output in the final form are available. This includes all exceptions which systems less integrated than the commercial data processing ones cannot process or only with huge effort. This means that any input information is entered into the machine just once and is also just processed once.

Only if this relevance of commercial electronic data processing has been clearly recognized, can organizationally desirable accounting systems be developed (Sandford Smith 1957).

Smaller and scientific computers are totally unsuitable for these tasks. They can only perform parts of functions, like punch card technology, which are out of question for electronic-integrated data processing. Approaches like that "use a patchwork technique by trying to fix a part of the company's data processing systems at a specific point in time without considering the rest of the system. Such a method resembles that of an amateur who wants to build a house. He does not create plans, but solves each problem when it occurs during the construction process... Then, of course, the whole house looks like patchwork" (Canning 1956, p. 30).

Let us consider the handling of data within the company's marketing area as an example of electronic-integrated data processing. Once all order data are entered into a data processing system, the accounting, statistics, and paperwork tasks of the following departments are integrated: order registration, sales, production planning and control, order tracking, shipment, backorder processing, order and delivery statistics, billing, account of sales, debtor accounts, storage of revenue data for cost accounting.

This already defines the limits for selecting such data processing systems. Decisive for the described tasks and similar ones are magnetic tapes and printer equipment in particular. In contrast, processing speed itself is of secondary importance.

A few words, spoken by Dr. Mittelsten Scheid on the special exhibition of auto- mation in April 1957 in Düsseldorf, may illustrate the mental tenor of these arguments once again. He said: "I would like to [...] underline that the thoughts forming the basis of automation must be applied to all management functions and to all functions that appear in the procedures of an organization. This also includes the entire administration, research, as well as sales, procurement, human resources management, etc.

Let me point out that I do not consider automation to be a mechanical process but a process which results from mental activity, from the attitude towards work."

\section{References}

Canning RG (1956) Electronic data processing for business and industry. Wiley, New York

Deutsch KW (1951a) Communication in selfgoverning organisations. Columbia University, New York

Deutsch KW (1951b) Models of communication and education. Columbia University, New York

Deutsch P (1956) Entwicklungstendenzen der Betriebswirtschaftslehre im Zeichen des technischen Fortschritts. ZfB 26(9):477-491

Gutenberg E (1951) Grundlagen der Betriebswirtschaftslehre Band I: Die Produktion. Springer, Heidelberg

Junkersdorff K (1957) Die Organisation: Mittel zum Zweck. ZfB 27(2):193-198

Kalveram W (1953) Industriebetriebslehre, 6. Aufl. Gabler, Wiesbaden

Mayer A (1956) Der arbeitende Mensch in unserer Zeit. ZfB 26(12):669-678

Pollock F (1956) Automation, Materialien zur Beurteilung ihrer ökonomischen und sozialen Folgen. Frankfurter Schriftenreihe zur Soziologie, Band 5

Sandford Smith J (1957) The management approach to electronic digital computers. Macdonald \& Evans, London

Schneider E (1949) Einführung in die Wirtschaftstheorie. Mohr, Tübingen

Wiener N (1948) Cybernetics, or control and communication in the animal and the machine. Wiley, New York 